\title{
Modelling Sunflower Yield Prediction at Field Scale
}

\author{
Inés Gudiño일 Vianel Rodríguez ${ }^{2}$ and Hernán Laurentin*1 \\ ${ }^{1}$ Biological Sciences Department, Faculty of Agronomy, Venezuela
}

${ }^{2}$ Plant Sciences Department, Faculty of Agronomy, Venezuela

*Corresponding author: Hernán Laurentin, Biological Sciences Department, Faculty of Agronomy, Central Western University Lisandro Alvarado, Barquisimeto, Venezuela

\section{ARTICLE INFO}

Received: 幽 December 30, 2019

Published: 幽 January 13, 2020

Citation: Inés Gudiño, Vianel Rodríguez, Hernán Laurentin. Modelling Sunflower Yield Prediction at Field Scale. Biomed J Sci \& Tech Res 24(4)-2020. BJSTR. MS.ID.004073.

Keywords: Helianthus annuus; Capitulum; Seed

\begin{abstract}
Yield prediction at field scale based on biomass samples is an important issue for agriculture, because farmers may be able to change the development course of the agricultural process to get better final results. The aim of the present study was to stablish the basis for getting a sunflower yield prediction model, for that, this study investigated the partition of dry matter in sunflower plants, and also investigated if the dry mass of the second pair of leaves is a good predictor of the dry mass of the whole plant. Two commercial hybrids were planted for two years in two types of soils, and dry matter for the above ground biomass was determined for the second pair of leaves (top to down) and rest of the plant in the three first sampling each year, and also for capitulum in the other 5 samplings each year. Significant differences $(\mathrm{P}<0.05)$ were identified only for Soil Types for the variables Second Pair of Leaves Dry Mass and Capitulum Dry Mass in the sampling dates at 81, 92 and 103 days after planting. Dry mass of capitulum represented $30 \%$ of dry matter of the whole plant. Dry mass of Second Pair of Leaves was regressed on Dry Mass of the Whole plant and resulted for both types of soil in determination coefficients $\left(\mathrm{R}^{2}\right)$ higher than 0.95 . By using of both results, an accurate model of yield prediction was obtained: at any age of the plant, dry mass of the second pair of leaves must be determined for predicting the whole biomass of the plant, and knowing that $30 \%$ of the dry mass of the whole plant is represented by capitulum, an accurate yield can be predicted.
\end{abstract}

\section{Short Communication}

Agriculture is an activity with high level of risk, due to it is subjected to many unpredictable factors, both natural [1] such as climate, and market-based such as prices [2]. For this reason, farmers face the problem to decide about the agricultural process at the same time that something occurs, such as insect attack, long dry period, or price fall; however, when farmers have to react to these conditions, they still do not have an accurate prediction about yield and total production in their fields, therefore decisions do not necessarily will be the best. Farmers could take the best decisions about the agricultural process, if they have good and reasonable predictions about the harvest. There are two approaches to help farmers to predict yield: without observation on the crop, and with observation on the crop. When prediction is carried out without observation on the crop, historical data of yield and weather are used to estimate future crop yield in agricultural processes that maybe have not started yet; there is no observation about the agricultural process, observation are about climatic conditions occurred in the past. This approach tries to find out climatic patterns to estimate crops yield, by means of several tools such as data mining $[3,4]$, time series, panel, and cross-sectional models [5].

On the contrary, yield prediction by means of observation on the crop is based on observations on the plant already established on the field to estimate the results of the actual agricultural process. This approach can be reached by using satellite imagery covering large areas, or by taking samples of the plant for obtaining some data to correlate to yield. In most of the case, satellite imagery is used to estimate yield in a broad geographical area in global, national, and regional scale, to monitor food security [6], and largescale crop production $[7,8]$. Complex indices are constructed by using plant reflectance, and these indices are correlated to crop yield for predicting it. The other approach, when part of the plant is sampled, covers a small area, and it takes or observe some organ(s) 
of the plant and correlate it to crop yield. This strategy is totally under farmers control, therefore is the only that can be used by the farmers to take decisions about their agricultural processes. This approach is the less expensive and the most accurate, because is based on the simplest relationship: development of one organ of the plant related to biomass of the commercial organ. In order this strategy can be practically useful for predicting yield, it has to evaluate vegetative organs, preferably since before capitulum appears on the plant. In this way it is possible to construct a curve since the first sampling few days after planting and predict the final result of the harvest.

There are several studies of correlation between morphological traits and yield in several crops such as maize $[9,10]$, wheat [11], rice [12], soybean [13], and sunflower [14,15] but they are used as information for selection programs, not for predicting the quantity to harvest of the commercial organ based on some parameter of vegetative organs. Sunflower (Helianthus annuus L.) is an important crop because a healthy and edible oil is extracted from its seeds, and this oil is highly consumed worldwide. Achene yield in sunflower is considered a trait highly variable because of the environment conditions [14]. There are two types of environment conditions, those predictable such as soil traits, and those unpredictable such as weather. Farmers may plan how to manage the soil to get good sunflower harvest, but they cannot manage the climate, therefore farmers decisions during the agricultural process related to necessary changes in the crop management as consequence of changes in environment, are immediate; if farmers do not have accurate predictions of yield, it is not possible to manage the crop in other more efficient way. The aim of the present study was to stablish the basis for getting a sunflower yield prediction model, for that, this study investigated the partition of dry matter in sunflower plants, and also investigated if the dry mass of the second pair of leaves is a good predictor of the dry mass of the whole plant.

\section{Material and Methods}

\section{Field Assay}

At fields of Experimental Station Miguel Luna Lugo, in Universidad Centroccidental Lisandro Alvarado, Cabudare, Lara state, Venezuela, forty rows of $12.5 \mathrm{~m}$ length, separated by $1.2 \mathrm{~m}$, were prepared. Twenty rows were placed on a sandy clay loam soil, and the other 20 rows were placed on a sandy loam soil. Ten rows of each soil type were sown with seeds of a commercial hybrids, and the other 20 rows were sown with seeds of other commercial hybrid. Seeds were separated by $0.50 \mathrm{~m}$, to have an approximate availability of 500 plants of each hybrid in each soil type. This experiment was repeated twice, in two years.

\section{Sampling}

Sampling was carried out randomly. Rows within hybrids and soil type were ordered randomly, and nine sampling points (plants) were chosen randomly on each row. Sampling was carried out each 11 days for 103 days, starting 26 days after planting. Each sampling date consisted in taking plants of the 9 sampling points within the row for only one row, for each hybrid in each soil type. Sampling consisted in taking the above ground biomass of the plants. For the three first sampling dates, when there was no flowers, all plants were washed and dried to the air, and afterward the second pair of leaves (from the top to down) was separated of the rest of the plant (stem and leaves). Both vegetal portions were placed separately in paper bags and dried in oven at $60^{\circ} \mathrm{C}$ for 48 hours. Mass of each portion was determined in a digital scale. For the other 5 sampling dates, when there was capitulum in all plants, the procedure was similar, but a third vegetal portion was obtained and consisted in the capitulum.

\section{Statistical Analysis}

Analysis of variance was performed for each sampling date and for each vegetal portion (second pair of leaves and rest of the plants in the three first sampling dates, second pair of leaves, capitulum and rest of the plant for the other ten sampling dates). For all combinations sampling date - hybrid - soil type, percent of each vegetal portion (respect to the whole plant, as sum of the vegetal portions) was determined. Simple regression was performed for dry mass of the second pair of leaves on sampling dates, and through all sampling dates for dry mass of the whole plant and dry mass of the second pair of leaves, the best models were chosen according the highest determination coefficient (R2).

\section{Results}

No interaction was detected in any of the analysis of variance, therefore there was no significant effect $(\mathrm{P}>0.05)$ for Year $\mathrm{x}$ Hybrid, Year x Soil Type, Hybrid x Soil Type, and Year x Hybrid x Soil Type (Figures $1 \& 2)$. The only significant effect $(\mathrm{P}<0.05)$ resulted for Soil Type for the variables Second Pair of Leaves Dry Mass and Capitulum Dry Mass in the sampling dates at 81, 92 and 103 days after planting; in all these cases dry mass resulted higher in sandy loam soil than in sandy clay loam soil. Due to absence of interaction, but significant effect for Soil Type, means for each hybrid in two years were averaged within soil type and sampling date. Table 1 displays partition of dry matter of the whole plant in percent of dry mass of the second pair of leaves, capitulum, and rest of the plant for two soil types and 8 sampling dates. Potential regression resulted with the highest determination coefficient for all regressions performed. Dry mass of the second pair of leaves for 8 sampling dates in sandy clay loam soil resulted in R2 $=0.9906$ (Figure 3 ), and in sandy loam soil in 0.9745 (Figure 4). Regression of dry mass of the whole plant on dry mass of the second pair of leaves was performed within each type of soil, resulting 0.9652 in sandy clay loam soil (Figure 5) and 0.9848 in sandy loam soil (Figure 6) (Table 1). 
Table 1: Average and standard deviation of dry mass percent of second pair of leaves, capitulum, and rest of the plant relative to whole plant dry mass across two years and two hybrids, for eight sampling dates in two soil types.

\begin{tabular}{|c|c|c|c|c|}
\hline Soil Type & $\begin{array}{c}\text { Sampling Date as Days after } \\
\text { Planting }\end{array}$ & $\begin{array}{c}\text { Dry Mass Percent of Second } \\
\text { Pair of Leaves }\end{array}$ & $\begin{array}{l}\text { Dry Mass Percent of } \\
\text { Capitulum }\end{array}$ & $\begin{array}{c}\text { Dry Mass Percent of Rest of } \\
\text { the Plant }\end{array}$ \\
\hline \multirow{8}{*}{ Sandy Loam } & 26 & $12.41 \pm 0.00$ & - & $87.59 \pm 0.00$ \\
\hline & 37 & $16.13 \pm 0.06$ & - & $83.87 \pm 0.06$ \\
\hline & 48 & $10.89 \pm 0.05$ & - & $89.11 \pm 0.05$ \\
\hline & 59 & $5.18 \pm 0.09$ & $9.14 \pm 0.03$ & $85.68 \pm 0.07$ \\
\hline & 70 & $3.48 \pm 0.12$ & $27.66 \pm 0.05$ & $68.86 \pm 0.09$ \\
\hline & 81 & $4.84 \pm 0.27$ & $25.97 \pm 0.19$ & $69.19 \pm 0.22$ \\
\hline & 92 & $4.59 \pm 0.08$ & $29.46 \pm 0.07$ & $65.95 \pm 0.08$ \\
\hline & 103 & $4.91 \pm 0.36$ & $27.50 \pm 0.22$ & $67.59 \pm 0.28$ \\
\hline \multirow{8}{*}{ Sandy Clay Loam } & 26 & $14.71 \pm 0.06$ & - & $85.29 \pm 0.06$ \\
\hline & 37 & $15.79 \pm 0.02$ & - & $84.21 \pm 0.02$ \\
\hline & 48 & $10.23 \pm 0.05$ & - & $89.77 \pm 0.05$ \\
\hline & 59 & $5.09 \pm 0.27$ & $8.89 \pm 0.18$ & $86.01 \pm 0.26$ \\
\hline & 70 & $4.89 \pm 0.18$ & $26.72 \pm 0.12$ & $68.39 \pm 0.15$ \\
\hline & 81 & $6.21 \pm 0.18$ & $24.99 \pm 0.15$ & $68.80 \pm 0.17$ \\
\hline & 92 & $4.98 \pm 0.57$ & $33.77 \pm 0.19$ & $61.31 \pm 0.19$ \\
\hline & 103 & $4.59 \pm 0.19$ & $33.71 \pm 0.11$ & $61.70 \pm 0.15$ \\
\hline
\end{tabular}

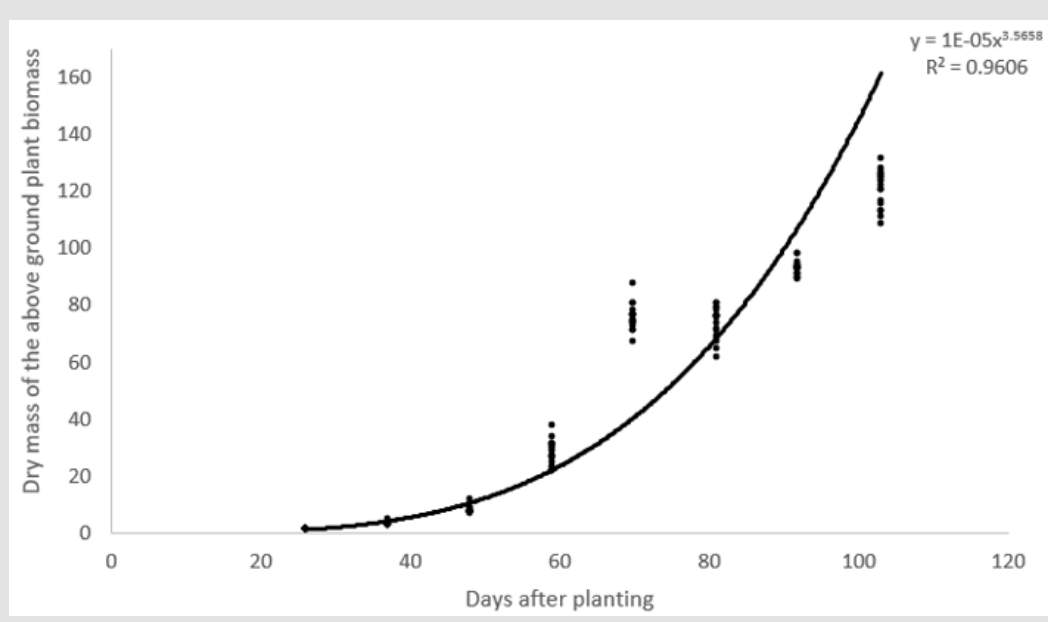

Figure 1: Dry mass of the above ground plant biomass of sunflower, averaged on two hybrid in two years in a sandy clay loam soil.

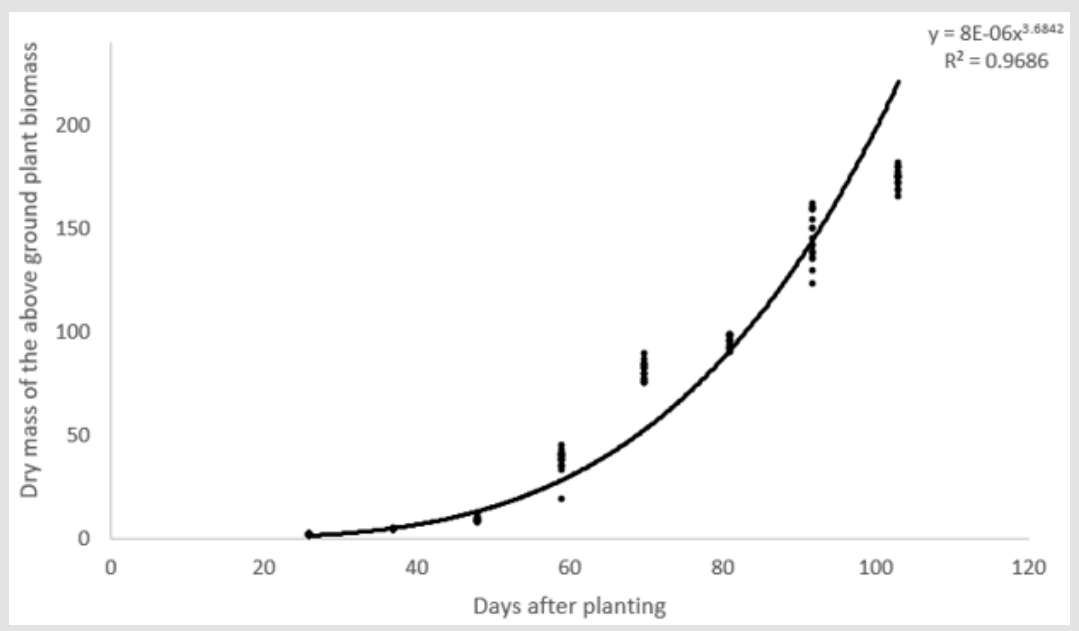

Figure 2: Dry mass of the above ground plant biomass of sunflower, averaged on two hybrid in two years in a sandy loam soil. 


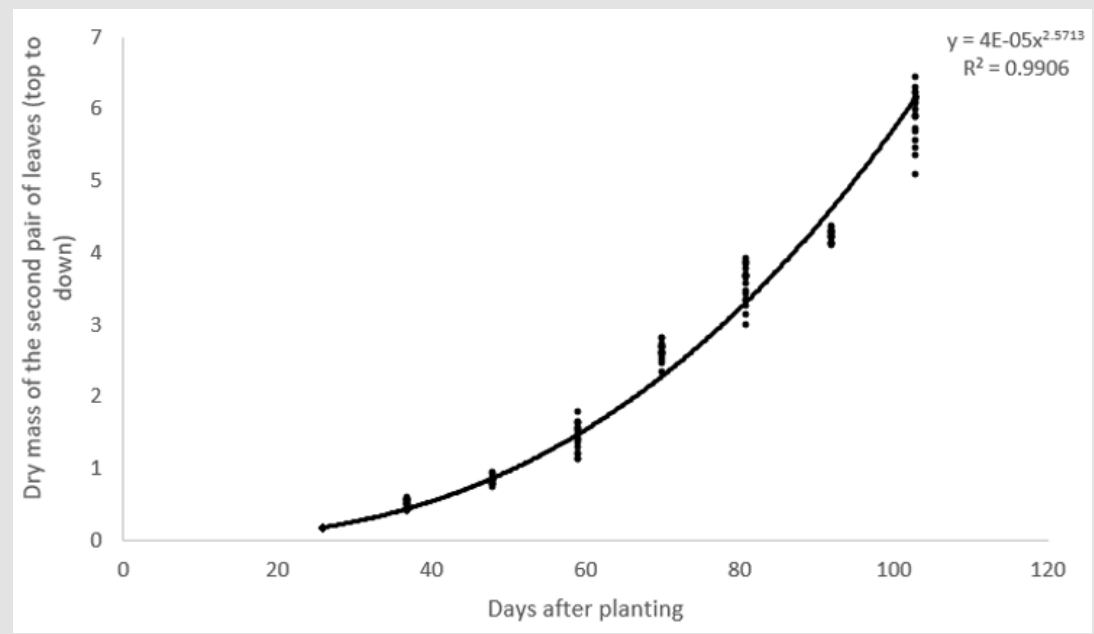

FIGURE 3: Dry mass of the second pair of leaves of sunflower, averaged on two hybrid in two years in a sandy clay loam soil.

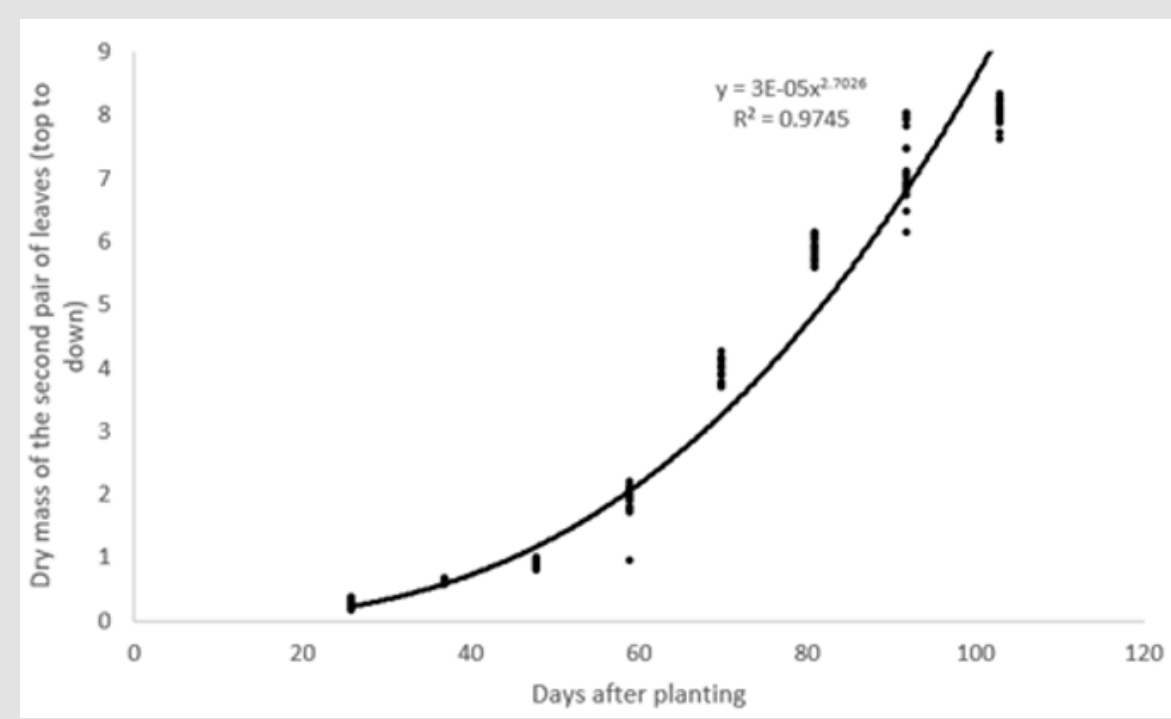

Figure 4: Dry mass of the second pair of leaves of sunflower, averaged on two hybrid in two years in a sandy loam soil.

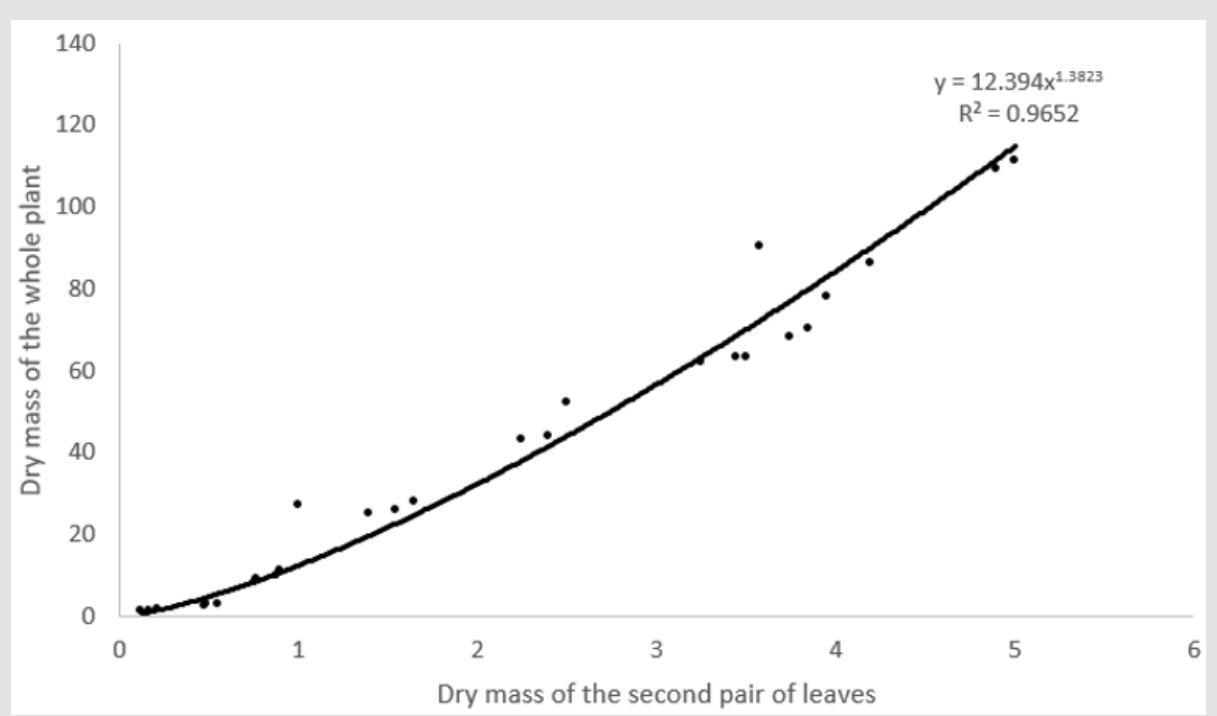

Figure 5: Relationship between dry mass of the whole plant and dry mass of the second pair of leaves for data obtained on a sandy clay loam soil. Equation and determination coefficient inside the graph. 


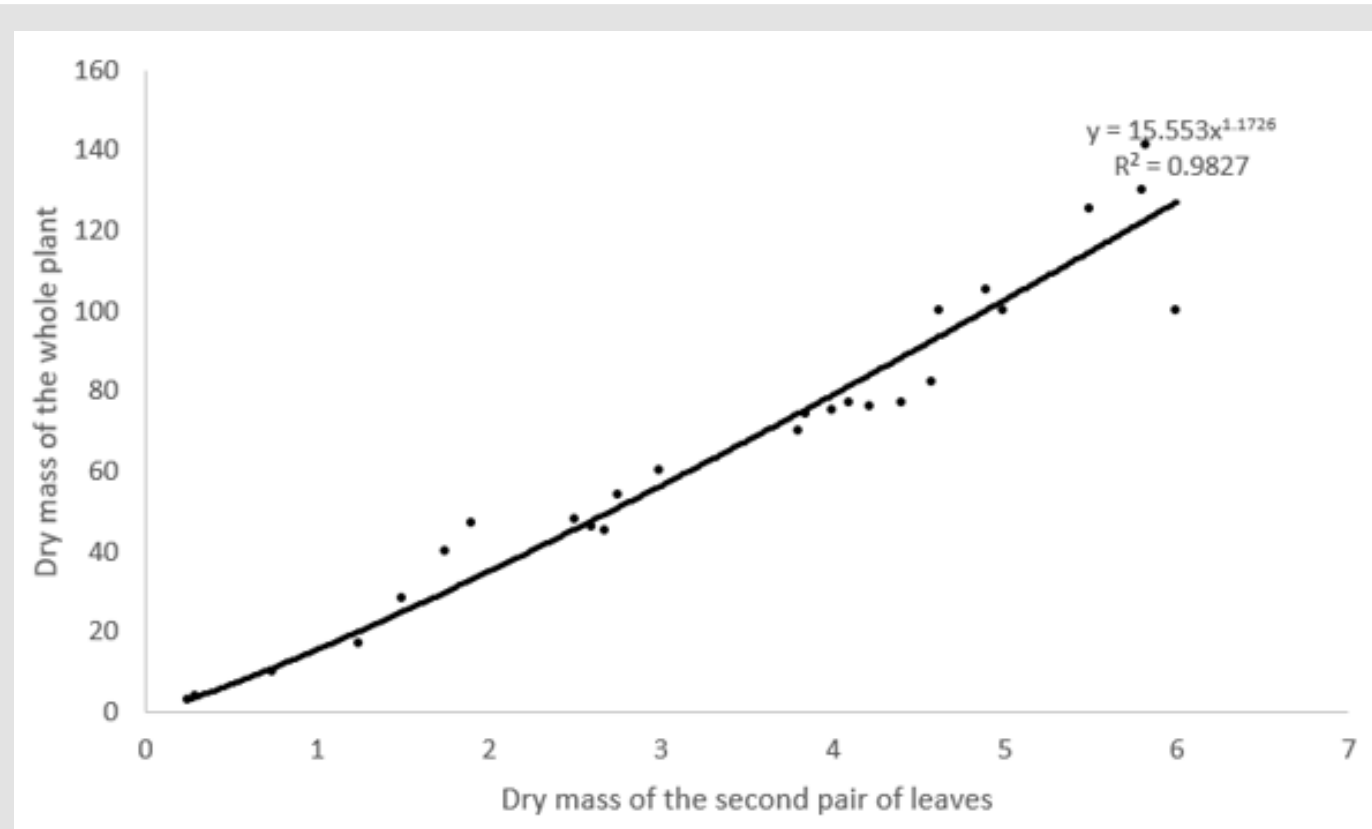

Figure 6: Relationship between dry mass of the whole plant and dry mass of the second pair of leaves for data obtained on a sandy loam soil. Equation and determination coefficient inside the graph.

\section{Discussion}

Partition of dry matter of the above ground biomass of the sunflower plants resulted between 27.28 and $33.82 \%$ for capitulum at the day 103 after planting. Harvest index is defined as the ratio of seed yield to the total biomass in the plant [16], and ratio between seed mass and capitulum mass is about $60 \%$ [17], it means that harvest index for present study was around 18\%. Magnitude of harvest index must be considered low when it is compared to recent reports with values between 27 and 31\% [17], 34 and $44 \%$ [18], however, sunflower phonotypic variability is also expressed for harvest index because some studies have reported values so low such as 3,4, and 9\% [19]. One of the objectives of sunflower breeding is to increase harvest index, however it is a trait highly influenced by environment, and it can explain the broad range for the magnitude of this trait.

The close relationship between dry mass of the second pair of leaves and dry mass of the above ground plant biomass opens opportunities for sunflower yield prediction based on direct observations of the agricultural process, and also simple nutritional diagnosis of the plant [20]. Yield prediction based on leaves sampling is very accurate, it is associated to photosynthetic capacity [21], and it is evaluating a direct measure of the plant biomass growth, in the same units of the commercial production (mass of seeds). Several traits have been reported as associated to sunflower yield, such as days to $50 \%$ of plant to maturity, plant height, and number of leaves per plant [22], but they have not been used as yield predictors, and as we know, there is not previous studies that try to correlate the second pair of leaves with yield. The proposed model for yield prediction in sunflower is the following:
1) Determination for each field lot, or the minimum area of the field which want to be controlled, of two equations by regression, the first one obtained from dry mass of above ground plant biomass vs. days after planting (Equation 1), and the second one obtained from dry mass of second pair of leaves vs. days after planting (Equation 2).

2) Prediction must be on the expected result at the harvest according to dry mass of the second pair of leaves determined in any day of the cycle, therefore, it must be fixed a specific day for harvesting.

3) When a sample of the second pair of leaves is taken, term $\mathrm{X}$ of the equation 2 must be found out (which will be called X1). This X1 must be compared to the actual day of the sampling, if they are the same, the prediction of production will be which is indicated for the equation 1 for the harvest day when $\mathrm{X} 1$ is placed. If they are different, it must be calculated how many days before or after resulted for the equation relative to the actual date.

4) If $\mathrm{X} 1$ from the equation resulted in some days before of the actual sampling date, prediction of production will be the results of the equation 1 when $\mathrm{X}=$ (Harvest Day - X1 obtained from equation 2). 5. If $X$ from the equation resulted in some days before of the actual sampling date, prediction of production will be the results of the equation 1 when $\mathrm{X}=$ (Harvest Day $-\mathrm{X} 1$ obtained from equation 2).

\section{Conclusion}

1) For planting conditions used in this study, capitulum dry mass reach about $30 \%$ of the plant dry mass. 
2) Dry mass of second pair of leaves from the top to down is an accurate predictor of above ground plant biomass.

3) A simple model of sunflower yield prediction at field scale is proposed and consists in obtaining regression equation of dry mass of second pair of leaves on sunflower cycle days, and also equation of dry mass of above ground plant biomass on sunflower cycle days. With both equations, yield prediction can be performed from a simple datum of second pair of leaves dry mass, since first days after planting.

\section{References}

1. Jankelova N, Masar D, Moricova S (2017) Risk factors in the agriculture sector. Agric Econ - Czech 63(6): 247-258.

2. Rosa F, Taverna M, Nassivera F, Iseppi L (2019) Farm/crop portfolio simulations under variable risk: a case study from Italy. Agric Econ 7 (8)

3. Raorane A, Kulkarni R (2012) Data mining: an effective tool for yield estimation in the agricultural sector. International Journal of Emerging Trends \& Technology in Computer Science 1(2): 75-79.

4. Ramesh D, Vishnu Vardhan B (2015) Analysis of crop yield prediction using data mining techniques. International Journal of Research in Engineening and Technology 4(1): 470-473.

5. Lobell D, Burke M (2010) On the use of statistical model to predict crop yield responses to climate change. Agricultural and Forest Meteorology 150(11): 1443-1452.

6. Kolotii A, Kussul N, Shelestov A, Skakun S, Yailymov B, et al. (2015) Comparison of biophysical and satellite predictors for wheat yield forecasting in Ukraine. The International Archives of the Photogrammetry, Remote Sensing and Spatial Information Sciences XL-7/W3: 39-44.

7. Torbick N, Chowdhury D, Salas W, Qi J (2017) Monitoring rice agriculture across Myanmar using times series Sentinel-1 assisted by Landsat- 8 and PALSAR-2. Remote Sensing 9(2): 119.

8. Al Gaadi K, Hassaballa A, Tola E, Kayad A, Madugundu R, et al. (2016) Prediction of potato crop yield using precision agriculture techniques. Plos One 11(9): e0162219.

9. Silva T, Moro G, Moro F, Santos D, Buzinaro R (2016) Correlation and path analysis of agronomic and morphological traits in maize. Revista Ciência Agronômica 47(2): 351-357.

10. Reddy R, Jabeen F (2016) Narrow sense heritability, correlation and path analysis in maize (Zea mys L.). SABRAO Journal of Breeding and Genetics 48(2): 120-126.

\section{ISSN: 2574-1241}

\section{DOI: 10.26717/BJSTR.2020.24.004073}

Hernán Laurentin. Biomed J Sci \& Tech Res

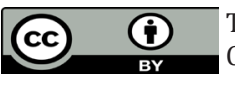

This work is licensed under Creative Commons Attribution 4.0 License

Submission Link: https://biomedres.us/submit-manuscript.php
11. Ahmad I, Mahmood N, Khaliq I, Khan N (2016) Genetic analysis for five important morphological attributes in wheat (Triticum aestivum L.). The Journal of Animal \& Plant Sciences 26(3): 725-730.

12. Bhutta M, Munir S, Qureshi M, Shahzad A, Aslam K, et al. (2019) Correlation and path analysis of morphological parameters contributing to yield in rice (Oryza sativa) under drought stress. Pak J Bot 51(1): 7380.

13. Ghanbari S, Nooshkam A, Fakheri B, Mahdinezhad N (2018) Assessment of yield and yield component of soybean genotypes (Glycine max L.) in north of Khuzestan. Journal of Crop Science and Biotechnology 21(5): 435-441.

14. Supriya S, Kulkarni V, Shanker goud I, Lokesha R, Govindapa M (2016) Genetic variability studies for yield and yield components in sunflower (Helianthus annuus L.). Electronic Journal of Plant Breeding 73(3): 737741.

15. Golabadi M, Golkar P, Shahsavari M (2016) Genetic analysis of agromorphological traits in promising hybrids of sunflower (Helianthus annuus L.). Acta Agriculturae Slovenica 105(2): 249-260.

16. Tyagi V, Dhillon S, Kaushik P (2018) Stability analysis of some novel cytoplasmic male sterile sources of sunflower and their hybrids. Helia 41(69): 153-200.

17. Sheoran P, Sardana V, Singh S, Kumar A, Mann A, et al. (2016) Agronomic and physiological assessment of nitrogen use, uptake and acquisition in sunflower. International Journal of Plant Production 10(2): 109-121.

18. Coelho F, Dutra A, Pitombeira J (2016) Effect of spatial arrangement on the production components and yield of sunflower. Revista Ceres 63(2): 214-222.

19. Ram J, Singh U, Singh S, Krishna B (2018) Study of genetic diversity in sunflower (Helianthus annuus L.). International Journal of Current Microbiology and Applied Sciences 7(5): 2266-2272.

20. Malavolta E, Vitti G, Oliveira S (1992) Evaluación de estado nutricional en plantas. Principios y aplicaciones. 2a edc. POTAFOS. Piracicaba SP. Brasil.

21. Osnas J, Lichstein J, Reich P, Pacala S (2013) Global leaf trait relationships: mass, area, and the leaf economics spectrum. Science 340(6133): 741744.

22. Sheeza K, Razzaq A (2019) Association among Morphological and Yield Related Traits in Different Accessions of Sunflower (Helianthus annuus L.). Russian Agricultural Sciences 45: 128-136.

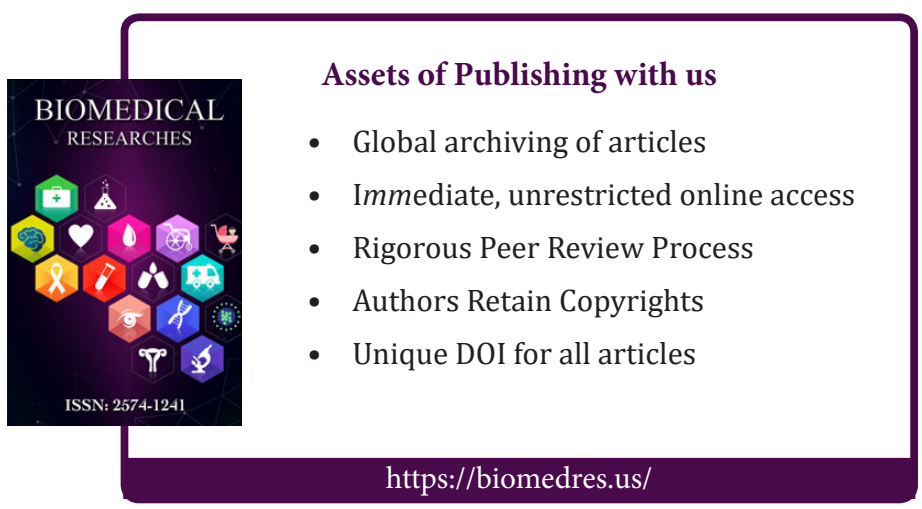

